\title{
Critical Thinking Focus Applied on Student-Centered Approach
}

\author{
Júlia Justino \\ Polytechnic Institute of Setúbal \\ Centre for Energy and Environment Research (CINEA) \\ Setúbal, Portugal \\ julia.justino@estsetubal.ips.pt
}

\author{
Silviano Rafael \\ Polytechnic Institute of Setúbal \\ Setúbal, Portugal \\ silviano.rafael@estsetubal.ips.pt
}

\begin{abstract}
The implementation of the student-centered approach in the classroom allowed the design of active didactic spaces for learning and the exercise of potential critical thinking, besides the technical and scientific objectives. This paper presents the pedagogical techniques applied to trigger the integration of the routine of thinking critically on the thematic issues of a course unit. The reasoning method used to exercise the potential critical thinking and observe the students' change of attitude is also presented.
\end{abstract}

Keywords-student-centered approach, critical thinking, active learning, engineering education.

\section{INTRODUCTION}

In a constantly changing world, transversal skills are much appreciated by employers because of their contribution to high performance in the engineering profession in its various aspects [1]. Thus, in addition to technical and scientific skills, curricula and course restructurings should better reflect the urgent need to include more and unequivocally the transversal skills to be developed along the academic path [2]. This means that transversal competences are increasingly unavoidable and inseparable from the syllabus. This logic of parity skills acquired by students, consequently reflected on the learning objectives, should be translated at the level of the course unit through the teaching and learning activities. In this context, the implementation of the student-centered approach makes a lot of sense because it allows working the technical and scientific skills together with the transversal skills, simultaneously during classroom time. Also, a good interaction between the different course units during term time, aiming to exercise the referred competences in a complementary way to pool efforts, would contribute to the consolidation of the results achieved by students. However, in this context, there is still a long development path to go in terms of communicating joint objectives and raising the awareness of teachers for the aggregation of efforts and pedagogical training needs in order to apply properly supported learning methods and techniques and to understand its didactics and terms.

The transversal competence presented in this paper is the critical thinking or critical sense. According to the World Economic Forum, critical thinking is considered the second most important competency, the first being solving complex problems [3]. Hence, critical thinking is one of the vital competencies for a modern education since it prepares students for active life, supporting autonomy and lifelong learning ability. In fact, the large amount of information available nowadays in the various types of media may not be well applied if the user does not have critical sense to tailor filter, debug, reject or compare the information for its own benefit and the benefit of the entire community. However, teaching critical thinking skills to university students is a major educational challenge [4].

This study was developed over the two academic years 2017-18 and 2018-19 in the mandatory course unit Electrical Machines of the last-year degree in Electrical Engineering where the student-centered approach was implemented for the first time, properly aligned with the learning objectives and assessment. In the previous three academic years of 2014-15, 2015-16 and 2016-17, the traditional teacher-centered approach was the pedagogical methodology applied in this course unit. The teacher and the topics covered were the same during these five academic years.

\section{Research Methodology}

During term time two research methods were applied: a quantitative method and a qualitative method $[5,6]$. These methods were sequentially or simultaneously applied according to issues raised and data to be evaluated.

In the quantitative method, based on students' investigations and assessments, two different surveys were carried out during the term time: initial and final. The initial survey, with multiplechoice questions, aimed to identify the students' profile in the use of critical sense in problem solving.

This survey was carried out by the students in the first class, before starting the academic work. The final survey, again with multiple-choice questions, sought to register the students' opinions regarding the initial objectives and their expectations. All surveys were anonymous in order to protect the students' identity and privacy.

The qualitative method, based on the interpretative approach given by the teacher's personal observation in classes upon the students' behavioral attitude along the learning process, provided useful information about how the critical thinking was being conducted, interpreted and experienced, giving additional information in addition to the surveys' questions. 


\section{WHAT IS CRITICAL THINKING}

There are many definitions and measures of critical thinking. This variety can make it difficult for researchers and teachers to understand or agree on the key components of good critical thinking, which may prevent their ability to construct an integrated theoretical account of how best to train critical thinking skills. In the absence of greater clarity in relation to the components of critical thinking skill and the way these components work together in the context of solving critical thinking problems, it can be difficult to design critical thinking training programs $[7,8]$. In fact, although critical thinking is a competence that can be learned, practiced and developed according to the need of the professional activity, the teaching and learning strategies that teachers usually employ, as well as most commonly used curriculum materials, are content focused. In most cases, these resources were designed only to support the transmission of knowledge disseminated by the teacher $[9,10]$.

\section{MODEL DEFINITION}

In this paper the concept of critical thinking is given by the exercise of intellectual activity that seeks relevant, reflective, responsible and reliable knowledge about the object in question, supporting the acceptance, believe or performance of a decision. The result of reasoning always requires some logic, coherence, some ranking or order of priority or importance, and a thinking structure quality that is rational, reasonable and meaningful. It is important to experiment strategies that can lead to the exercise of this competence in the context of a learning space with a teacher and focused on the study themes and its learning objectives. Using exercises based on logical schemes, problem solving, debate or discussions as a way of developing critical thinking depends on the opportunity created by the teacher in the classroom to work it out, on the one hand, and the ability of the student to relate and manipulate his knowledge, on the other hand. In general, it is not enough for teachers to mention and encourage the use the critical sense in their classes in order to really develop it. Most students are expected to have hard time understanding what the teacher purports to achieve with critical thinking. The main teacher's difficulty on developing activities for the exercise of the students' critical thinking skills lies in the apparent complexity and fuzziness of the critical thinking's meaning $[11,12]$. In fact, "we should be teaching students how to think. Instead, we are teaching them what to think." [13]. However, the way of thinking when solving a scientific problem can be generically transcribed and established as a generic supporting model of the thinking process. Therefore, a stepbased model on problem solving was proposed, established and explained to the students and then applied, consisting of the reflection steps sequence presented in Figure 1.

The first step is to interpret the problem or statement in order to assimilate the starting conditions and the aim to achieve. The second step, depending on the nature of the problem, is to split it into smaller parts or to synthesize or fragment the information given. The third step is to question "What do I know about each part of the problem?" and relate and/or compare it with previous knowledge acquired, namely to relate or compare the fundamental or synthesized aspects of the problem with related fundamental aspects of individual knowledge on the subject. In the fourth step, based on logical reasoning, one must infer or deduce the validity of the knowledge-based relationship or comparison concerning the question defined in the previous step. The fifth step is to decide if the deduction is well founded. If so, the decision is taken to apply the knowledge to the part of the problem. If there is no basis for application, a gap in the personal knowledge on the subject has been detected and it is necessary to return to step three and relate and/or compare with external information using other sources of knowledge such as a book or the internet to find a similarity issue. The sixth step is to confirm whether the application was successful or not and the result obtained fits into the context of the problem. If confirmed, then the problem has been solved with a valid solution. If the result does not make sense, since it is not consistent with the context of the problem, then the reasoning developed so far is not valid and it is suggested to return to step 2 to review or formalize a new fragmentation of the problem, repeating the procedure in order to detect some reasoning error throughout the steps.

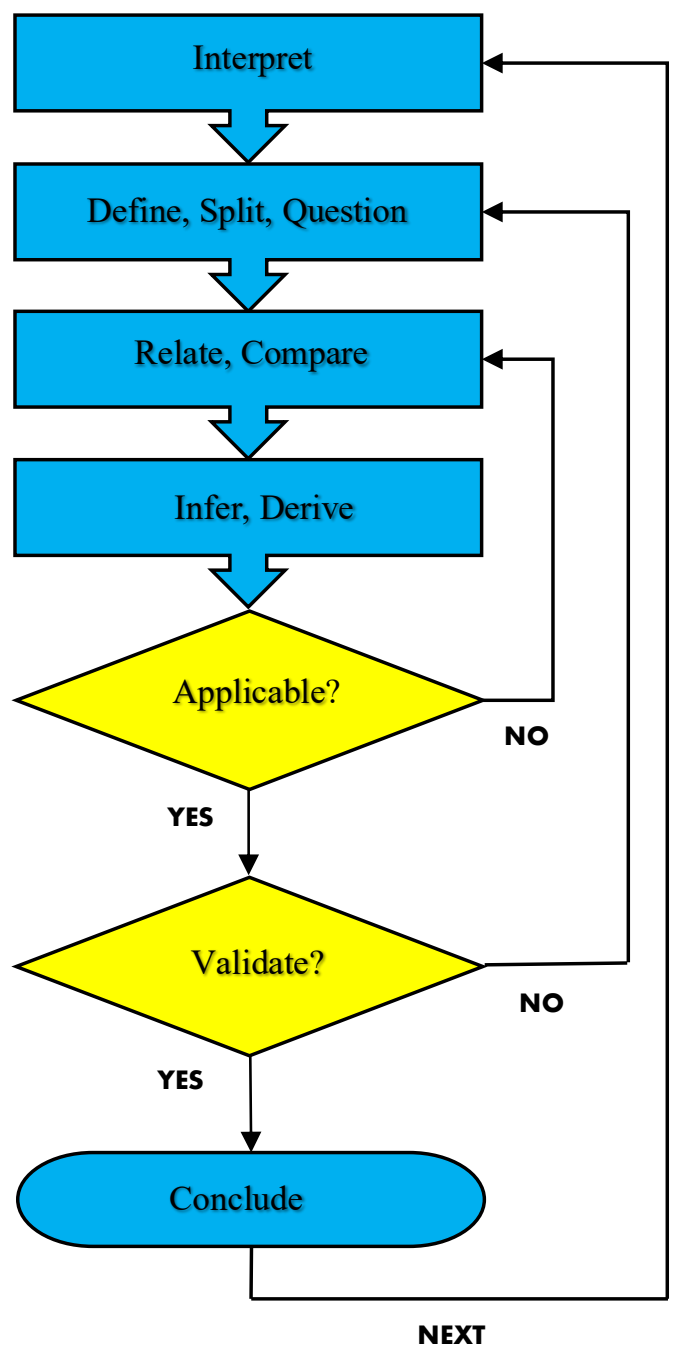

Fig. 1. Step-based model on solving problems critically.

\section{EXPERIMENTAL APPLICATION}

To foster critical thinking, it is necessary to internalize its theoretical principles in order to apply them. One way is by doing exercises. So, in this case study specific exercises were 
developed to enhance critical thinking in theoretical classes, laboratory classes and formative assessment. Learning activities were designed in the context of active learning techniques such as inquiry-based learning [14], problem-based learning [15], collaborative work and gallery walk. In those learning activities the application of the step-based model referred to in the previous chapter was fostered through gradual exercises in terms of demand and difficulty. Students were previously informed.

An initial group exercise consisted of analyzing an image by asking related questions, requesting reasoned answers for those questions and checking the veracity of the answers given, namely an image of a simulation of a solenoid's magnetic field. It is important for students not to be familiar with the image presented but having some basic theoretical concepts. The intention was for students to be able to dissect the image using their imagination, raising several doubts/ questions and managing the answers given by identifying, relating and comparing it with fundamental physical phenomena in electrical engineering. In this context, the inquiry-based learning technique was applied supported by a process of imagination in order to consider the multiple perspectives of the actions and consequences of the laws of physics and their links to reality. Initially, when the image was presented, students were led to become aware of their knowledge, by applying or relating it to the image. Although it would be easily possible to ask more than a dozen questions/doubts about a new image posted, in practice no more than 3-5 questions were asked by students. It should be noted that this exercise is not comparable with brainstorming because it is necessary to relate the image to the laws of physics, being a way to encourage students to raise questions, asking themselves what they do know about the subject. For several reasons the answers and open debate of reasoning are meager at an initial stage. However, the repetition of this type of exercise throughout term time, using different images according to the contents covered, contributes to the students' evolution in terms of increasing the ability to ask relevant and quality questions and/or doubts, as well as greater care regarding the answers shared during the debates.

Within the variety of exercises to boost critical thinking, the problem-based learning technique was also applied. This pedagogical technique was applied to solve real-world exercises related to the topic covered, justifying the results obtained and linking them to reality. The opposite was also applied by giving numerical solutions of a problem and then asking to analyze their accuracy with good reason. Problem solving was carried out individually or in groups, depending on the learning objectives of each topic covered. Case studies were presented to students, with errors to be detected and corrected. The quality of the solutions and answers addressed by students on problem solving, in the context of classroom and group work, was verified and evaluated at the stage of knowledge levelling under the supervision of the teacher, where constructive criticism and other working groups' assessment were also evaluated in order to avoid passivity. Thus, discussion and reasoned opinions regarding each presentation were fostered.

Critical thinking was also boosted through formative tests where more elaborate reasoning questions were asked. These questions were discussed later and solved at the knowledge sharing and levelling stage where corrections could be crossed, i.e., made by other students. If so, both the evaluator and the evaluated students were evaluated by the teacher.

Laboratory classes are an easier environment to generate spaces for inquiry-based learning exercises on scientific and technical demonstrations. This can be accomplished by defining the laboratory procedures' basis in the execution of an essay with characteristics of the object under study, experimentally testing the results obtained for validation and background information, criticizing the numerical simulation results of the mathematical model of the object under study and comparing it with the experimental results, including model programming errors, its detection and correction. Essentially, tasks in which students do not have to just literally follow a laboratory work guide, leaving no room for, gradually, constructive and critical thinking.

Outside the classroom critical thinking can be supported through constructive critique of a lecture, seminar, video, or part of a text or scientific technical article, analyzed by the working group and discussed at the beginning of the next class.

This case study was conducted over the two academic years 2017-18 and 2018-19 in the mandatory course unit Electrical Machines of the last-year degree in Electrical Engineering to a sample of 25 students.

\section{OUTCOMES OF THE APPLICATION}

Over two years of application of these several learning activities throughout term time it was observed a general improvement in the quantity and quality of the questions and answers shared by the students. It was also achieved, as intended, to train students to create their own individual reflective habit of practicing critical thinking before raising easy or thoughtless doubts. The exercises specifically included in the teaching-learning activities were the fundamental element for student's critical thinking development. In addition, the pedagogical structure was adapted to create a recursively environment favorable to the application of the step-based model of thinking previously presented by gradually implementing more elaborate, complex and challenging exercises.

In the academic year 2017-18, the results of the survey carried out at the beginning of term time showed that only $19 \%$ of the students often or always applied critical sense in problem solving while $81 \%$ stated to sometimes or rarely apply critical thinking. In the following academic year 2018-19, the results of the initial survey were not much different, with $23 \%$ of the students stating to frequently or always apply critical sense in problem solving while $77 \%$ sometimes or rarely applied it.

On the final survey of the academic year $2017-18,54 \%$ of the students felt to have developed critical thinking in problem solving or individual questions while $46 \%$ exercised it sometimes. In the following academic year 2018-19, survey's results reveal that $86 \%$ of the students stated to have developed critical thinking in solving problems or issues while $14 \%$ stated to only have exercised it sometimes. This indicator emphasizes the importance of developing critical thinking intentionally from the first-year course units due to the diversity of learning styles and patterns. However, all students of these two academic years expressed that the student-centered approach allowed the 
exercise of critical thinking to the detriment of teacher-centered approach.

One effective contribution on triggering critical thinking was an increase of more than $20 \%$ in the success rate of the course unit in 2017-18 and 2018-19, compared to the three previous academic years, 2014-15, 2015-16 and 2016-17, that never reached $60 \%$, as shown in Figure 2 below.

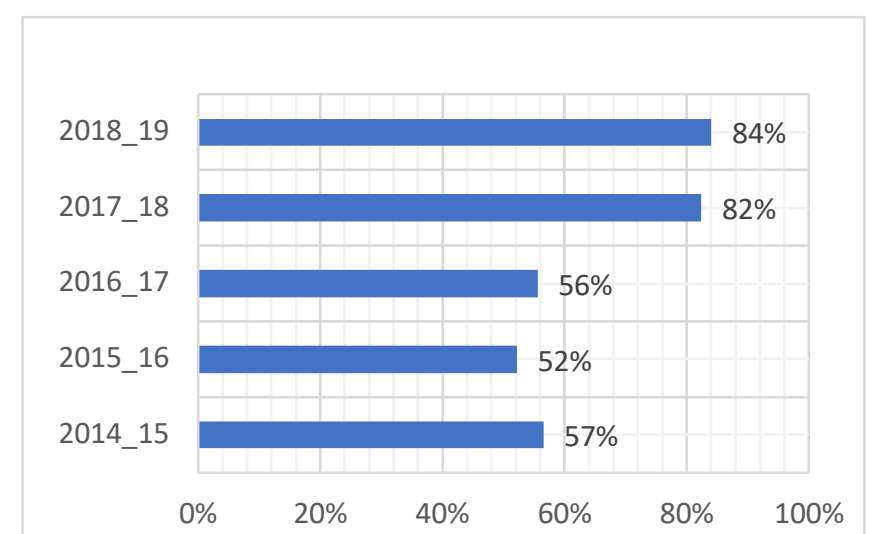

Fig. 2. Success rate of the course unit over the last 5 academic years

\section{CONCLUSIONS}

Some inertia was observed initially when applying the stepbased model of critical thinking above-mentioned, due to its conscious construction and its implementation on the proposed problems. The critical thinking structure was progressively integrated by the consequent identification of crucial questions and doubts, the demand for gaps' resolution and the sharing of solutions, which are essential in the construction of the students' knowledge. During this process students consulted several elements of study, besides those available, and talked to each other within the group work whenever new information or knowledge arrived, exercising argument and reasoning. To ensure a good implementation of the process it is vital that the teacher gives continuous feedback on the students' critical thinking evolution. So, improving critical thinking requires attention and dedication both from students and teacher.

The student-centered approach contributes positively to the exercise of conscious critical thinking. Students have spontaneously expressed that they feel better prepared for unfamiliar situations and greater security and confidence in themselves, their own knowledge and their reasoning. Another consequence is, by focusing on the knowledge already acquired in other contexts, the construction of the students' new knowledge within a course unit is enhanced.

Finally, critical thinking could be boosted if properly framed and applied in all course units of an engineering course from the first academic year. This would allow students' knowledge, already acquired in other contexts, to contribute more actively to the construction of new knowledge of any course unit, enhancing the students' academic performance as well as their professional performance. In addition, the application of the step-based model of critical thinking in a group work also allows other soft skills to be exercised and consequently developed.

\section{REFERENCES}

[1] B. Schulz, "The importance of soft skills: Education beyond academic knowledge", Nawa Journal of Communication, 2008, vol. 2, $\mathrm{n}^{\mathrm{o}}$ 1, pp. $146-154$

[2] R. Bancino and C. Zevalkink, "Soft Skills: The New Curriculum for HardCore Technical Professionals", Techniques: Connecting Education and Careers, 2007, vol. 82, n 5, pp. 20-22.

[3] A. Gray, "The 10 skills you need to thrive in the Fourth Industrial Revolution", Future of jobs Report, World Economic Forum, 2016. Available:https://www.weforum.org/agenda/2016/01/the-10skills-you-need-to-thrive-in-the-fourth-industrial-revolution/

[4] D. T. Willingham, "Critical thinking: Why is it so hard to teach?", American Educator, 2007, vol. 31, pp. 8-19.

[5] A. Tashakkori and C. Teddlie, "Mixed methodology: Combining qualitative and quantitative approaches", Applied Social Research Methods Series, vol. 46, Thousand Oaks, CA: Sage Publications, 1998.

[6] D. W. Shaffer and R. C. Serlin, "What good are statistics that don't generalize?", American Educational Research Association, 2004, vol. 33, $\mathrm{n}^{\circ}$ 9, pp. $14-25$.

[7] C. Dwyer, M. Hogan and I. Stewart, "The promotion of critical thinking skills through argument mapping", chapter in Critical Thinking, Christopher P. Horvath and James M. Forte, Eds., Nova Science Publishers, 2011.

[8] R. H. Ennis, "A concept of critical thinking", Harvard Educational Review, 1962, vol. 32, no 1, pp. 81-111.

[9] R. M. Vieira, C. Tenreiro-Vieira and I. P. Martins, "Critical thinking: Conceptual clarification and its importance in science education", Science Education International, 2011, vol. 22, $\mathrm{n}^{\mathrm{o}}$ 1, pp. 43-54.

[10] D. F. Halpern, Thought and knowledge: An introduction to critical thinking [5th edition]. New York: Psychology Press, 2013.

[11] OECD. "Review of Higher Education, Research and Innovation: Portugal", February 2019.

[12] T. Kenyon, "Critical thinking for engineers and engineering critical thinking", 2nd International Conference of the Portuguese Society for Engineering Education, IEEE Xplore Digital Library, 2016, pp. 1-4, doi: 10.1109/CISPEE.2016.7777736.

[13] J. Lochhead and J. Clement, Cognitive process instruction: Research on teaching thinking skills. Philadelphia: Franklin Institute Press, 1979.

[14] M. N. Browne and S. M. Keeley, Asking the right questions: a guide to critical thinking [8th edition]. Pearson Custom Publishing, 2007.

[15] D. Norman, "Cognitive engineering and education", in Problem solving and education: Issues in teaching and research, D. T. Tuna and F. Reif, Eds., Erlbaum Publishers, 1980. 